DH Revista Humanismo

R. 10 y Sociedad

\title{
Introducción al superciudadano: la ciudadanía entre Nietzsche y el republicanismo ${ }^{ \pm}$
}

Introduction to the super-citizen: citizenship between Nietzsche and republicanism

\begin{abstract}
Andrés Gustavo Mazuera Zuluaga ${ }^{1^{*}}$, Estudiante de Derecho
${ }^{1}$ Estudiante de Derecho, Universidad de Medellín. Miembro activo del semillero de Teoría General del Derecho (TGD). Correo electrónico: gmazuera@gmail.com.
\end{abstract}

(Aceptado: 17 de noviembre de 2014)

\section{Resumen}

La propuesta republicana sobre el papel que debe de asumir la ciudadanía en la construcción y la consolidación de la democracia a través de la participación activa en los escenarios políticos lleva a cuestionarse: ¿hasta qué punto es posible alcanzar la figura de un ciudadano responsable y comprometido con la vida política? La respuesta obligada a la anterior pregunta parece apuntar a la educación de un ciudadano republicano como método efectivo para hacer frente a las dificultades que afronta la democracia. Sin embargo, esta virtud cívica exigida lleva a pensar que el ciudadano ideal de la democracia se parece más a un superhombre que al ciudadano común. El ciudadano republicano es una especie de superciudadano. Por este motivo, la comprensión de este ciudadano, que se debate entre sus preocupaciones privadas y las exigencias de la vida política, a partir de los obstáculos que encuentra Zarathustra cuando intenta enseñar una naturaleza sobrehumana, puede arrojar luces sobre el predicamento en el que se hallan los Estados democráticos cuando quieren educar un ciudadano con características más que humanas.

Palabras clave: ciudadanía, democracia, Nietzsche, republicanismo.

\section{Abstract}

The republican proposal regarding the role that citizenship must play in constructing and strengthening democracy through active participation in political scenarios raises this question: to what extent is it possible to achieve a responsible citizen, engaged in political life? The obligatory answer seems to point towards the education of a republican citizen

\footnotetext{
${ }^{\perp}$ Para citar este artículo: Mazuera Zuluaga, AG. Introducción al superciudadano: la ciudadanía entre Nietzsche y el republicanismo. RHS. Revista. Humanismo. Soc, Volumen 2 (2): 38-51

*Autor para correspondencia: Andrés Gustavo Mazuera Zuluaga. Universidad de Medellín, Medellín, Colombia. Correo electrónico: gmazuera@ gmail.com.
}

Revista. Humanismo.Soc. 2014; Volumen 2 (2): 38-51. 
as an effective method to deal with the problems democracy faces nowadays. However, this civic virtue suggests that the ideal citizen required by democracy is somehow a super-citizen. For this reason, understanding this type of citizen, one who struggles between their own private concerns and the demands of political life, on the basis of those obstacles encountered by Zarathustra in his attempt to teach the more-than-human nature, might shed light on the predicament of democratic states in trying to teach more-than-human features to a citizen.

Key words: deemocracy, citizenship, Nietzsche, Republicanism.

\section{Introducción}

El título predispone el curso del presente texto en torno a la idea del ciudadano y la figura del superhombre. Ciertamente la alusión a la filosofía de Nietzsche no pretende determinar la manera en que el autor concibe la figura del ciudadano o sus posturas políticas; sino más bien a la pretensión de plantear la estética del ciudadano ideal y las dificultades que se presentan a la hora de cumplir con la expectativa de un ciudadano verdaderamente democrático, a través de la experiencia que vive Zarathustra cuando quiere enseñar al superhombre.

El concepto contemporáneo del ciudadano democrático señala a un ciudadano con especialísimas características políticas, puesto que su condición no se obtiene simplemente por pertenecer al Estado, sino que se manifiesta constantemente en su compromiso por la vida en política y por la esfera pública, mediante la participación consciente, el ejercicio de sus derechos cívicos y el respeto por la institucionalidad democrática. Estos requerimientos probablemente sientan las bases para creer que en la actualidad no existe una ciudadanía auténticamente democrática.

En este sentido, el presente escrito se desarrollará en tres partes: un primer momento explicitará porqué se recurre a la existencia de un símil entre el ciudadano democrático y el superhombre nietzscheano; en un segundo lugar, se desarrollará la idea del ciudadano democrático y las dificultades que implica su consolidación por medio de la crítica al concepto de ciudadanía liberal; finalmente, se evaluará la estética del héroe nietzscheano como forma de comprender el ciudadano democrático ideal a través de la visión republicana.

\section{El superciudadano y Nietzsche}

Que la democracia requiera ciudadanos y gobernantes comprometidos con los ideales democráticos y con la vida política, es ciertamente una apreciación que no genera mayor oposición ${ }^{1}$. La moderna crítica a la concepción liberal del ciudadano conlleva a plantear una ciudadanía más participativa y preocupada por la vida política. Sin embargo, hasta qué punto esta consideración es verdaderamente ejercida en la práctica diaria, es en la actualidad una situación que debe ser reevaluada. La denominada crisis de la democracia (Arteta, 2009: 15-32) es una situación de amplio debate en los distintos círculos académicos de la ciencia política y de la filosofía política los cuales proponen pensar la ciudadanía a la luz de los nuevos problemas democráticos (Sassen, 2002: 9). Por este motivo, es importante plantear el interrogante sobre lo plausible que son las expectativas democráticas frente a la concepción de ciudadanía. Probablemente el tipo de ciudadano que exige la democracia moderna, es de una naturaleza superior y excepcional a la ciudadanía que en la praxis política se evidencia.

Al igual que manifiesta Nietzsche, el tipo de hombre que la democracia requiere, es una especie de superhombre o superciudadano. Los esfuerzos de la democracia deben ir encaminados a establecer la

\footnotetext{
1 "En el ámbito de la teoría política, los análisis sobre el concepto de la ciudadanía parecen converger de manera creciente en la necesidad de incorporar como un dato central de sus propuestas que ser ciudadano exige la adquisición de un conjunto de virtudes, la identificación con un conjunto de valores sin los que el mantenimiento de un orden social liberal y democrático se hace insostenible”. (Mougán, 2009: 222)
} 
forma en que se puede consolidar esta superciudadanía comprometida de forma completa con los valores democráticos. De este modo, se comienzan a notar algunas similitudes entre los retos que el mundo actual presenta a la democracia y los retos que en su momento tuvo que enfrentar Zarathustra para alcanzar un estado más alto de la naturaleza humana.

Nietzsche parte en una primera etapa de su pensamiento con una fuerte crítica a la manera de ser del hombre. La humanidad, según él, se encontraba en un fuerte nihilismo caracterizado por la renuncia a la voluntad del espíritu, la decadencia de los valores máximos y por la sumisión a preceptos morales que desconocían el poderío del hombre para crear y configurar su destino. Por lo anterior, es de suma importancia el lugar que tiene Zarathustra en la filosofía nietzscheana, dado que él mismo lo describe como: "el regalo más grande que le ha dado a la humanidad" (1993: 17). Zarathustra es el profeta que anuncia la llegada del superhombre a la tierra, el cual de alguna forma asumirá la tarea de ser el redentor de los fracasos humanos y reemplazará finalmente la naturaleza humana, por una naturaleza superhumana.

Ahora bien, la filosofía del superhombre es difícil de abarcar. No es claro completamente a qué se refiere Nietzsche cuando vaticina la venida del superhombre a la tierra. Lo que sí es evidente, son las características excepcionales que tiene esta nueva raza de hombres. El superhombre debe entenderse como la superación de la naturaleza humana en toda su dimensión existencial y moral.

La superación moral va dirigida hacia a la afirmación de la vida misma como máximo valor. De ahí que la trasmutación de todos los valores signifique que el superhombre es un ser que antepone su deseo por la vida sobre cualquier otra posibilidad. De este modo, lo terrenal, mundano y la personificación propia de la naturaleza animal del hombre son en principio concebidos como los valores por excelencia. A su vez, la superación de la existencia (atada de la afirmación de la vida), dispone que el superhombre es un ser consciente de sí mismo y de su esencia. Por este motivo, asume su propia vida y reconoce en ella el elemento dionisiaco que la dirige hacia el placer, la incoherencia, el dolor, la crueldad, las contradicciones y a la tragedia de una vida vivida con heroísmo.

Sin embargo, todavía no es claro por qué se pretende comprender la idea del ciudadano democrático a través de la filosofía del superhombre. De ninguna manera se quiere resaltar las inexistentes características políticas que tiene la figura del superhombre, ni que en efecto haya una concepción del ciudadano en Nietzsche. Éste nunca se ha destacado por sus aportes a la política y ciertamente tampoco por mostrar interés cívico-. No obstante, es necesario partir de la tesis según la cual el ciudadano democrático es una concepción eminentemente más alta que la de un ciudadano común o la de un súbdito ${ }^{2}$.

$\mathrm{Al}$ igual que en el caso de Nietzsche, se puede afirmar que la democracia moderna tiene su germen en una fuerte crítica a las ideas políticas que prevalecieron durante más de mil años. La relación que existía entre los individuos y el Estado era de la propia de emperador y súbdito. De este modo, el papel del ciudadano, políticamente hablando, consistía en la sumisión a la voluntad del regente y a la defensa del imperio. Desde que cae la república romana hasta la ilustración, la idea de la naturaleza que se tenía del individuo correspondía a su lugar como súbdito dentro imperio. En efecto, la ciudadanía romana -Status Civitatis (Medellín, 2009: 49) - consistía en una relación legal entre el imperio y sus asociados, por lo que cumplía la función de la romanización a través de la definición del ciudadano como miembro de una comunidad de la ley romana o Legalis Homo; en estricto sentido, el individuo podía identificarse al interior de la comunidad que determinaba sus derechos y obligaciones. Con posterioridad a la caída del imperio romano, el individuo perdió su capacidad de identificarse con un cuerpo normativo y la importancia de la ciudadanía fue relegada a un segundo plano. La primacía del cristianismo generó en occidente un cambio en el paradigma del individuo; éste en lugar de identificarse como miembro de un imperio, se reconocía a sí mismo como miembro de la iglesia y como buen cristiano.

${ }^{2}$ Esta excepcionalidad del ciudadano (republicano) que participa activamente en la democracia ha sido criticada entre otros por Habermas. (1999) 
La búsqueda de la salvación del alma reemplazo la posición política de la ciudadanía (Kartal, 2001: 123)

Con la llegada de la época moderna y las teorías contractualistas se empieza a vislumbrar una concepción de alguna forma diferente sobre el ciudadano. Aunque los Estados absolutistas concibieron la ciudadanía como la pertenencia de los súbditos al imperio -especialmente en los casos de Hobbes y Bodin (Kartal: 123) por medio de la figura del contrato social la relación entre el individuo y el Estado cobra un matiz distinto, puesto que la obediencia del súbdito estaba directamente relacionada con el cumplimiento de las obligaciones contraídas por el Estado ${ }^{3}$. De hecho, la propuesta de un contrato social sitúa al individuo en otra posición respecto del Estado, toda vez que entre ambos se configura la existencia de obligaciones correlativas. Este reconocimiento de la libertad humana y del lugar del individuo en la estructura del Estado, será la semilla para que a futuro se comenzara a reivindicar la protección de los ciudadanos frente al Estado y el ejercicio derechos políticos ${ }^{4}$.

La democracia moderna se nutrirá entonces de estos antecedentes y cambiará definitivamente, por intermedio de los principios democráticos de libertad e igualdad ante la ley, la percepción del hombre como un simple súbdito, por la figura de un ciudadano que tiene libertades y derechos políticos.

Contrario al superhombre, el ciudadano democrático es una figura un poco más fácil de describir. Este ciudadano se comprende solamente cuando se puede afirmar que existe una democracia instaurada como sistema político en un Estado. El ciudadano es igualmente un redentor, ya no de la existencia humana, sino de la vida política que se establece entre los hombres, toda vez que éste puede ejercer un espectro más o menos amplio de derechos cívicos y políticos. Se rescata la vida política como el espacio en el cual los hombres se encuentran unos con otros y se relacionan con el fin de perseguir objetivos comunes mediante el diálogo, la confrontación de ideologías y opiniones, y se pretende limitar al tiempo la cabida de tiranos o gobiernos totalitarios mediante la elección de los gobernantes a través del voto popular y la construcción de mecanismos que permitan una adecuada veeduría sobre aquellos. Lo anterior otorga una dimensión al ciudadano completamente superadora del súbdito, el cual estaba bajo unas fuertes limitaciones en su actuar político y es "un destinatario pasivo de deberes y mandatos" (Bovero, 2002: 92).

En consecuencia, se hace referencia a la participación política que de forma genérica se deriva de los derechos políticos de elegir y ser elegido, así como de los mecanismos institucionales dispuestos para hacer efectivos los derechos fundamentales entre los que se cuenta la libertad y la igualdad como presupuestos incondicionales de cualquier sistema democrático.

Sin embargo, esta dimensión de la ciudadanía democrática es únicamente parcial. El concepto de ciudadano moderno -heredado de la tradición liberal (Gargarella, 2002: 75)- ejerce unos derechos y está obligado a cumplir con unas obligaciones del orden normativo que se limitan a la prohibición de realizar determinadas conductas y a obedecer ciertos lineamientos de convivencia básica, no corresponde auténticamente a lo que significa ser ciudadano en una democracia. El reconocimiento del poder político que tienen los hombres no puede estar supeditado al eventual ejercicio de derechos políticos, sino que se corresponde igualmente a las obligaciones políticas que se tienen por vivir en una democracia.

En efecto, el ciudadano democrático se debe preocupar por la consolidación efectiva de los espacios políticos, por el desarrollo del bien común de la sociedad y por asumir una vida de compromiso y responsabilidad con la política en sí misma.

El ciudadano democrático no puede ser, de ninguna manera, apático a la participación política. La garantía

\footnotetext{
${ }^{3}$ Sobre este tema surge como hito importante la función que cumplía el parlamento británico en lo relativo a la aprobación de nuevos tributos bajo la premisa fundamental: nulla taxatio sine repraesentatio. (Rubio, 2007: 54).

${ }^{4}$ Es necesario resaltar la posición que obtuvo el parlamento en Inglaterra después de la Revolución gloriosa de 1689, con la adopción de la de la monarquía parlamentaria a través del Bill of Rights precedente directo de las declaraciones liberales que vendría con posterioridad en la Europa continental. (Rubio, 2007: 55).
} 
de las libertades políticas tiene su correlativa obligación de hacer uso de las mismas con el objetivo de mantener en movimiento el espacio político ganado; se configura como el deber ético que subyace a los derechos políticos. Por esta razón, el ciudadano verdaderamente democrático sobrepasa rápidamente la definición tradicional de la ciudadanía, este tipo de ciudadano tiene características muy excepcionales, toda vez que debe comportarse políticamente de conformidad con lo que significa vivir en una democracia.

Es importante resaltar que asumir un comportamiento político no significa simplemente llevar una sana convivencia con los demás. La política no se resume en compartir un espacio común a los hombres, sino que significa comprometerse $y$ responsabilizarse de las prácticas democráticas, de las decisiones comunes e individuales que tienden a contribuir al bien general, al progreso y a la consolidación de los valores democráticos. En otras palabras, las prácticas democráticas solamente pueden fortalecer y mantener vigentes los ideales democráticos en la medida que esta participación sea asumida de forma fuerte, esto es, tanto la participación en la toma de decisiones a través de los medios institucionales dispuestos para ello, como la participación en la actividad cívica y la preocupación por las problemáticas que aquejan la vida política. Que la naturaleza política de los seres humanos sea sintetizada únicamente en la vida social de los mismos, parece ser un error derivado de una probable mala traducción de la expresión aristotélica del Zoon Politikon como Animal Socialis:

[n]o es que Platón o Aristóteles desconocieran -o se desinteresaran- el hecho de que el hombre no puede vivir al margen de la compañía de sus semejantes, sino que no incluían esta condición en las especificas características humanas; por el contrario, era algo que la vida humana tenía común con el animal, y sólo por esta razón no podía ser fundamentalmente humana. La natural y meramente social compañía de la especie humana se consideraba como una limitación que se nos impone por las necesidades de la vida bilógica, que es la misma para el animal humano que para las otras formas de existencia animal [...] (Arendt, 2005: 51)

De esta manera, mientras que la naturaleza animal de los hombres los lleva a la necesidad de convivir y formar comunidades para el mutuo beneficio y la supervivencia de la especie, la característica política genera una forma de actuar radicalmente distinto, puesto que a diferencia de los animales, los hombres pueden encontrar un lugar para el diálogo, la persuasión y la acción en la esfera pública. En otras palabras, lo social hace referencia a lo común, es decir, el lugar en donde los seres humanos se encuentran, relacionan y conviven por gracia de las necesidades originadas de la vida y limitaciones biológicas; lo político, vivir en una polis, hace específico énfasis tanto al espacio común en donde se presentan las relaciones intersubjetivas, como a la manera en que los hombres hacen uso del diálogo y la acción política para encontrarse en una esfera en donde satisfacer las carencias biológicas no está en el primer orden del día. En el espacio político pueden surgir los intereses y objetivos comunes mediante la discusión y la palabra que enlazan la vida pública de los hombres; participar activamente del futuro del pueblo mediante el debate, la argumentación corresponden al compromiso de los hombres frente a su condición política. La distinción que Arendt realiza entre lo social y lo político se sustenta en la necesidad de evitar confundir la esfera privada del hombre con su esfera pública:

Según el pensamiento griego, la capacidad del hombre para la organización política no sólo es diferente, sino que se halla en directa oposición a la asociación natural cuyo centro es el hogar (oikia) y la familia. El nacimiento de la ciudad-estado significó que el hombre recibía además de su vida privada, una especie de segunda vida, su bios politikos. Ahora todo ciudadano pertenece a dos órdenes de existencia, y hay una tajante distinción entre lo que es suyo (idion) y lo que es comunal (koinon). (2005: 51-52)

Así, eventos como la fusión entre el Estado y las concepciones cristianas evidenciadas durante el medioevo, la postura totalizante de las relaciones económicas presentada por el marxismo demuestran para Arendt que lo social cobró en ocasiones una fuerte apariencia política y fundamentan la necesidad de separar lo social y lo político (2005: 61-70); es decir, las preocupaciones privadas, aunque sean de la comunidad en general, fueron invadiendo el escenario político hasta el punto de suplantarlo. Por esta razón, es pertinente escindir el lugar en donde la coacción de las necesidades físicas o espirituales de los hombres determinan su conducta, de la esfera política en donde se acude como hombre libre para configurar el espacio propicio para el uso de la palabra, el consenso y el disenso para la construcción de objetivos comunes. La diferenciación no hace referencia únicamente a quiénes 
podían concurrir al ágora para ser oídos - de donde eran excluidos los esclavos, niños y mujeres- sino porque en la esfera pública el hombre asume una actitud alejada de sus preocupaciones privadas y biológicas. El hecho que en la esfera pública se puedan debatir problemáticas sociales no implica la socialización de lo político, puesto que en este sitio no son las necesidades apremiantes lo que motivan a los hombres, sino la apuesta por el diálogo, el entendimiento y a mostrar quiénes son (2005: 208).

De acuerdo con lo anterior, el ciudadano está sumergido en dos ámbitos de existencia, por un lado debe de atender a sus cuestiones privadas, y por otro lado, actuar en la esfera pública, puesto que solamente de esta forma puede identificarse a sí mismo como un ser libre. Por consiguiente un ciudadano que no hace uso de sus derechos políticos y asume una responsabilidad conforme a sus obligaciones democráticas, no puede estar verdaderamente comprometido con la vida política y por ende no es un ciudadano democrático, por lo que permanece atrapado en su aspecto meramente biológico. En este punto radica realmente la naturaleza superior del ciudadano democrático, dado que renuncia a la pasividad y a la indiferencia de la vida política para introducirse de manera efectiva en la misma. No obstante, aquí también se evidencia lo complicado, escaso y extraordinario de ciudadanos auténticamente democráticos.

Las similitudes que existen entre el superhombre y el súper-ciudadano comienzan a ser más claras. Ambas figuras comparten al menos dos características: primero, se presentan como la superación de una naturaleza inferior de seres humanos o seres políticos respectivamente; en segundo lugar, cada uno debe de cumplir con unos requerimientos excepcionales y específicos que no son de comunes en la vida fáctica.

La pregunta obligada en este punto es: ¿de qué manera se consigue una ciudadanía verdaderamente democrática? Cuando se plantea el interrogante sobre la manera en que se garantiza que haya ciudadanos responsables y comprometidos con la vida política de una democracia, la respuesta automática tiene un tinte educativo ${ }^{5}$. La réplica democrática se sirve de la enseñanza de una cultura política con el objetivo de construir una sociedad de personas preocupadas por la vida política y por la prolongación en el tiempo de los valores democráticos que permitan la supervivencia de este sistema político (Peña, 2009: 100).

Esta posibilidad de haber encontrado la forma de construir un individuo superior a través de la educación no es exclusiva de la democracia. De hecho, cuando Zarathustra advierte la venida del superhombre siempre se presenta a él mismo como un educador mediante el uso de la siguiente afirmación: Ich lehre euch den Übermenschen (Yo os enseño al superhombre) (Nietzsche, 2011: 46). Aquí la enseñanza para el profeta tiene una particularidad muy especial, él se acerca a educar a los hombres puesto que reconoce que ellos no son el superhombre que está esperando; identifica así una carencia y por medio de la enseñanza que proporcionan sus parábolas desea llenar este vacío.

Justamente lo propio ocurre cuando el sistema democrático quiere en la actualidad educar a la ciudadanía en torno a los valores de la democracia. Enseñar presupone la carencia de ese algo que se enseña. Así pues, que la democracia requiera educar denota el reconocimiento a la ausencia de ciudadanos verdaderamente democráticos. Ahora bien, esta ausencia de ciudadanos democráticos no está dada porque no haya ciudadanos que vivan en una democracia, sino porque el ciudadano ideal que exige la democracia, es de alguna manera un ciudadano que se sale de lo usual tanto en el aspecto político como humano.

De esta manera, la democracia moderna se enfrenta al difícil reto de educar una ciudadanía que se halla reacia a sacrificar su individualidad y a comprometerse responsablemente con la vida política. Por este motivo, identificar las dificultades que se experimentan cuando se pretende instaurar una raza superior de ciudadanos, puede arrojar luces sobre el camino que se debe de seguir para alcanzar a concebir un ciudadano que sea verdaderamente democrático. La experiencia de Zarathustra es pues, en este particular caso, una manera

\footnotetext{
${ }^{5}$ La tendencia republicana que ha cobrado fuerza en el debate sobre la ciudadanía que debe de tener un Estado democrático "ha insistido en la necesidad de inculcar la virtud cívica de modo institucional, la familia y la escuela hasta las diversas formas de servicio al bien común". (Rubio, 2007: 21)
} 
de ilustrar sobre lo que representan los esfuerzos de la enseñanza del superhombre.

\section{La complejidad del superciudadano}

Es necesario resaltar la rapidez con que Zarathustra se da cuenta de las dificultades de su tarea educativa, e inclusive, de su imposibilidad. Tal vez prematuramente, el profeta desiste de la reivindicación del superhombre ante la multitud individuos. Zarathustra decide regresar a la montaña porque en el pueblo no ha sido escuchado: "y se ríen: no me entienden, no soy yo la boca para estos oídos" (Nietzsche, 2011: 51). La derrota que sufre la enseñanza del superhombre connota en principio que la comunidad no está dispuesta a aceptar su propia carencia, lo que se ve manifestado en su fuerte apatía y burla frente a las enseñanzas de esta naturaleza superior.

Por esta razón, no es desafortunada la comparación que se hace entre el ciudadano democrático y el superhombre. Existe más de un motivo para querer comprender las deficiencias en las que se ubica la democracia. Educar para una democracia lleva implícito la voluntad de querer formar una naturaleza superior, labor que no es fácil puesto que, como lo sufre Zarathustra tempranamente, el superhombre no se encuentra todavía en el mundo, de la misma manera que aún en la actualidad, los ciudadanos democráticos parecen estar cada vez más negligentes con los valores democráticos ${ }^{6}$. La similitud entre los sentimientos de aquellos hombres que se burlan del superhombre y los sentimientos que reflejan los ciudadanos en las democracias actuales a lo largo del globo son manifiestas. La apatía hacia la vida política, la indiferencia hacia el compromiso cívico y la irresponsabilidad con los procesos democráticos han sido fuente de diversas y variadas reflexiones.

Estas consideraciones giran alrededor del comportamiento deficiente que desempeñan los ciudadanos en los Estados modernos; con el fin de determinar en qué consisten concretamente las características excepcionales del superciudadano, es menester identificar la esfera en la cual se debe mover un verdadero ciudadano democrático cuando se le compara con el ciudadano común, es decir, aquel que no es auténticamente democrático. La actividad será por consiguiente comparativa y pretende resaltar, a través de las diferencias, que la superciudadanía se encuentra bastante etérea; aunque es discutible hasta qué punto puede afirmarse el fracaso de las democracias modernas como sistema político, sí podrá evidenciarse el fracaso de la ciudadanía democrática de la actualidad.

$\mathrm{Al}$ respecto, el primer aspecto a ser tenido en cuenta es la esfera a la que pertenecen las acciones de los ciudadanos en general. Una vez más es menester servirse de la diferenciación que hace Hannah Arendt en La Condición Humana (2005) sobre la esfera pública y la esfera privada: pertenece a la esfera privada la individualidad del hombre y sus inmediatas relaciones familiares. En este sentido, en la esfera privada (2005: 71-78) se hallan los intereses personales de los seres humanos, su moral personal, la concepción propia del bien, sus deseos y, fundamentalmente, sus contingencias biológicas. Igualmente se manifiesta en la esfera privada las relaciones familiares, en tanto éstas se presentan se manera directa e inmediata en la vida íntima del individuo. Los asuntos familiares, aunque hallan contacto y convivencia con otros seres humanos, corresponde a la esfera que permite el recogimiento y el alejamiento del mundo público (2005: 55).

Por oposición, pertenece a la esfera pública todas las actividades que el hombre desarrolla junto a otros. La esfera pública se presenta cuando el hombre ha salido de su esfera privada y deja de preocuparse por sus intereses individuales y asume su lugar como ser político. En este orden de ideas, la convivencia, la búsqueda de objetivos comunes, la participación política, el encuentro de opiniones y las acciones encuentran su asidero en esta esfera. Solamente en este sito el hombre puede brillar entre los otros, puesto que se presenta como el lugar de encuentro. En esta esfera se halla fuertemente arraigado el ejercicio de derechos políticos que se entienden en la medida que existen relaciones intersubjetivas y la preocupación por las decisiones y el futuro de la comunidad. Se deduce

\footnotetext{
${ }^{6}$ Precisamente, la crítica republicana a la ciudadanía liberal establece que el primero de los males derivados de la tradición liberal consiste en la alienación provocada por el distanciamiento entre los ciudadanos y las políticas del Estado, lo que conlleva finalmente a la ausencia de la ciudadanía en la vida pública. (Gargarella, 2002: 82)
} 
entonces que el sitio en el cual se puede dar vía a las actuaciones de los seres humanos como ciudadanos es en la esfera pública; la ciudadanía se desarrolla en la medida que se actúa con los otros y se inserta en la vida política (2005: 60).

Con todo, los distintos ámbitos a los que hacen referencia estas dos esferas suponen una disyuntiva. La existencia de una esfera privada y una esfera pública, es decir, lo individual y propio de la singularidad humana, y por otro lado lo común, aquello que se establece con el fin político, configura una diferenciación probablemente antagónica entre los intereses particulares y los intereses comunes. La posibilidad latente, y en ocasiones materializada, de individuos que antepongan sus intereses privados en el campo de la esfera pública en contra vía de los intereses comunes; o individuos que se segreguen completamente de la vida pública, surge como la dificultad primigenia que debe de afrontar la educación de un ciudadano democrático.

La esfera privada establecida como lugar de recogimiento y de escisión entre la individualidad del hombre y las relaciones políticas junto a los otros, puede generar la manifestación de ciudadanos que no participan de la vida política ni se involucran en la convivencia. Es importante indicar que este tipo de ciudadanos apáticos no son quienes hacen un daño directo a los valores democráticos, en otras palabras, no son delincuentes, homicidas o corruptos, sino que su naturaleza está circunscrita a preocupaciones meramente particulares, las cuales buscan ser satisfechas alejados de la vida pública. Así entonces, este tipo de ciudadanos no son una antítesis de los ciudadanos democráticos, se hallan más bien en una especie de limbo político, toda vez que no pertenecen a la población activa y comprometida con la democracia, pero tampoco pretenden vulnerar los derechos democráticos; dicho en otras palabras, no es ni un ciudadano que desee llevar una vida en común, pero tampoco es un ciudadano que hace un daño directo e intencional para violar los principios de la convivencia intersubjetiva. Es por consiguiente una apatía a la vida pública, a la vida política y un desinterés por ejercer las libertades que se tienen.
De tal forma, mientras que el ciudadano democrático hace uso de su potestad de accionar en la vida pública, es decir, actúa en la medida de las posibilidades políticas, el ciudadano pasivo no actúa, sino que omite su participación política. Desde este punto de vista, el ciudadano pasivo se retrae de las preocupaciones políticas comunes. Por lo anterior resulta ilustradora la comparación que hace Savater para referenciar la oposición entre un ciudadano cualquiera y un auténtico ciudadano democrático: Ciudadanía a la romana, lo que equivaldría a la ciudanía pasiva; y Ciudadanía a la griega, lo que equivale a la ciudadanía democrática (Savater, 2007: 12).

La ciudadanía romana sirve para identificar un ciudadano que cumple a cabalidad sus deberes jurídicos, sin que éste se preocupe o se interese por la vida política. A los ciudadanos se les brindaba derechos y obligaciones por su calidad especial de ciudadanía, no obstante, éstos no tenían potestades políticas en lo referente a la toma de decisiones políticas; los ciudadanos romanos, que se ceñían a la ley y actuaban conforme a las normas, aunque llamados ciudadanos, estaban obligados a estar impávidos, omitir y estar indiferentes a las realidades sociales y políticas. Es importante señalar que no se puede hablar de un único tipo de ciudadanía romana, puesto que ésta mutó en repetidas ocasiones durante la etapa de la república, el principado y finalmente con la constitución del imperio que se extiende la ciudadanía romana a todos los habitantes del imperio mediante el decreto antoniniano de 212 promulgado por Caracalla (Rubio, 2007: 45-49). Es finalmente esta extensión de la ciudadanía a todo el imperio lo que Nietzsche llamará "El principio Nacional" (2004: 64). La nacionalización de la ciudadanía sin que ésta pueda significar algo concreto en términos políticos, es para Nietzsche la manifestación más propia que el imperio romano ha barbarizado la ciudad-estado griega, y por lo tanto no puede alcanzar una meta más alta (2004: 64).

Distinto era en la antigua Atenas, en donde los ciudadanos sí tenían un papel protagónico en la toma de decisiones de la polis y en la construcción del espacio para la política. Los hombres libres concurren, no solamente al cumplimiento de sus obligaciones como ciudadanos pertenecientes a una polis, sino que por medio de la palabra y la acción se introduce a la vida pública; los hombres son oídos y reconocidos en su 
individualidad en el ágora el cual era el sitio destinado para la aparición pública de su ser

Aquí la visión de Nietzsche presenta un fuerte antagonismo entre lo deseable de la naturaleza del superhombre y el mantenimiento del Estado ${ }^{8}$. El autor reconoce que la cultura griega estaba imbuida en un profundo servicio al Estado (2004: 61). Para él la figura del ciudadano se ha construido sobre la idea de una ciudadanía griega que está al servicio del Estado, y que éste a su vez pretende guardar la cultura a través de la educación: "un ser muy egoísta y aislado nunca podría promover la cultura” (2004: 62).

El ciudadano que se enfrasca en la esfera privada vivirá en sociedad por el simple hecho de que ya está inmerso en ella, necesariamente estará en conjunto y en comunidad porque, como hombre que es, necesita relacionarse con otros. Pero esta relación no será nada más que biológica y utilitaria; significa en última instancia el abandono de la vida política de la cual no se siente ni parte ni interesado. La preocupación de todo hombre se centrará en su individualidad, en mantener para sí un espacio donde sólo él está y nadie lo interrumpa, en su vida privada él es señor y dueño. $\mathrm{Al}$ respecto dice Ortega y Gasset:

\section{"[n]oten ustedes que esta maravillosa facultad que el hombre tiene de libertarse transitoriamente de ser esclavizado por las cosas implica dos poderes muy distintos: uno, el poder de desatender más o menos tiempo el mundo en torno sin riesgo fatal; otro, el tener dónde meterse, dónde estar, cuando se ha salido virtualmente del mundo." (Ortega y Gasset, 1958: 300)}

La cualidad del hombre de ensimismarse y salirse del mundo para sus meditaciones, introducirse en sí, en sus ideas y, en última instancia, en $s u$ mundo, es un elemento riesgoso para conseguir la consolidación de una superciudadanía. El excesivo ensimismamiento, la eterna estancia dentro de sí, sin querer salir y volver a enfrentarse al mundo político, la vida pública, de la cual se escapó, terminará en la formación de un ermitaño que se encuentra en lo alto de una montaña, alejado de todo el mundo y de los demás, preocupado sólo en su mundo.

Por oposición, la figura del superciudadano propende por evitar la pasividad del ciudadano y la materialización del compromiso democrático. El superciudadano, el ciudadano democrático, es una renuncia a ensimismarse eternamente en un pequeño núcleo de la vida propia, y abrir ese núcleo de la vida privada a la vida política que se comparte con los otros. Es por esto que el ciudadano está llamado es a ser un actor que interactúa con otros actores. Distinto a quien se aleja y no quiere separarse del mundo público, el superciudadano debe interactuar con los otros, buscar a sus semejantes ahí dónde ellos estén, intercambia opiniones, escucha las ajenas y sostiene las propias, emerge en la plaza pública y la esfera política para compartir, para estar al tanto y participar de ese espacio que sólo se puede concebir cuando ejerce su libertad política (Savater, 2000: 159).

La característica excepcional del superciudadano no puede hacer referencia a otra cosa que a su actuar consciente. No significa lo anterior que en la democracia moderna todos los ciudadanos tengan apatía por la vida pública, sino que por regla general no hallan su lugar en la esfera pública. Aunque los fuertes sistemas de socialización acerquen a los seres humanos en su convivencia, ha habido un profundo olvido de lo político. Parece apenas lógico entonces suponer que el súuperciudadano hace uso pleno de sus libertades, y en especial de sus libertades políticas que lo califican como miembro dinámico de un Estado, pues es participando en las decisiones colectivas, referéndums, elecciones y demás expresiones de la democracia, que se puede mostrar como un agente presto a comprometerse con la realidad del Estado. La democracia necesita de ciudadanos realmente decididos a vivir la realidad política, que sustenten los ideales democráticos y que luchen por mantener una convivencia sana, sin permitir el ensimismamiento en la esfera privada de ser. Pues tal y como lo afirma Bobbio recurriendo a Stuart Mill:

\footnotetext{
${ }^{7}$ En el caso de la ciudadanía griega tampoco puede pretenderse hablar de un único tipo (Rubio, 2007: 17-36).

${ }^{8}$ En efecto, a pesar de que Nietzsche tiene un desprecio por el Estado democrático, lo cual queda evidenciado cuando afirma: " $y$ esta es la mentira que desliza su boca: yo, el Estado, soy el pueblo" (Nietzsche, 2011: 101).
} 
[...] si debiesen prevalecer los ciudadanos pasivos, con mucho gusto los gobernantes convertirían a sus súbditos en un rebaño de ovejas dedicadas únicamente a comer pasto una al lado de la otra (y, agregaría yo, a no lamentarse aun cuando el pasto escaseara). (Bobbio, 1986: 25)

Una ciudadanía que no está preocupada por tomar las riendas de la libertad que le ha sido concedida está generando la crisis democrática de los Estados modernos. Constant evidenció lo anterior con mayor pericia y severidad al afirmar en De la libertad de los antiguos comparados con los modernos: "El peligro de la libertad moderna consiste en que, absorbidos por el disfrute de nuestra independencia privada $y$ por la búsqueda de nuestros intereses particulares, renunciemos con demasiada facilidad a nuestro derecho de participación en el poder político" (Molina, 2009: 608). Evidentemente, un ciudadano abstemio a la vida en común recae en un peligro para la continuación de las garantías de la libertad.

En este mismo sentido, Bauman considera que la libertad del hombre que se crea en la modernidad presenta un inconveniente para el concepto de unidad y más aún para la idea del "ciudadano". De este modo, la figura del ciudadano, que en principio representa la unidad, el consenso, la idea de apoyo colectivo y la toma de decisiones a través de los pilares democráticos de la igualdad, el discurso, la persuasión y el bien común, se ve truncado por el factor del disenso individual, de la ciudadanía pasiva, la búsqueda del bien particular y personal en detrimento de la idea del bien común y el bien-estar de la sociedad en general. Bauman establece que los conceptos de individuo de iure e individuo de facto, determinan la forma en que la ciudadanía ha perdido su compromiso democrático: el primero hace referencia a aquella persona que se encuentra en una especie de limbo, en donde no logra acertar en sus decisiones y es individuo por el solo hecho del azar, pero no parece tener la convicción propia de serlo, esto es, su apatía a la vida política no es consciente; el segundo, es aquel que ha logrado interiorizar la idea de individualización, aquel que ha caído en cuenta de su lejanía con la vida pública y su desinterés por la esfera política, es, por así decirlo, el verdadero ciudadano pasivo consciente de su condición (2003: 41).

En este orden de ideas, la mayor dificultad que tiene la democracia en la enseñanza de una ciudadanía verdaderamente democrática está en torno a la lejanía de los ciudadanos de la esfera pública. La reducción de la injerencia del Estado en los aspectos individuales de los ciudadanos y la abundante cantidad de libertades que supone la vida en una democracia, genera igualmente la ausencia de necesidad por sumarse a la vida política, puesto que su esfera privada ha abarcado casi en su totalidad la existencia del ciudadano. El superciudadano además de ejercer sus libertades políticas también debe preocuparse por la sustentación, prosperidad y desarrollo del Estado en que habita. En la medida que el ciudadano es un ser político, no puede olvidarse de su responsabilidad en la vida pública.

La naturaleza del ser humano lo lleva a estar en comunidad con el otro, a compartir, convivir y a generar sistemas de colaboración entre los grupos para propender tanto por el bienestar de unos como de otros. Sin embargo, como ser político, está siempre condicionado a hacer uso de su discurso y su acción política, las cuales sólo pueden manifestarse en la esfera pública. Éste es el punto de inflexión que diferencia un ciudadano democrático de un ciudadano corriente; el superciudadano debe de mantener el equilibrio entre la esfera pública y la esfera privada, de este modo logrará preocuparse tanto por una como por otra.

Así pues, se concluye que la superior naturaleza del ciudadano auténticamente democrático radica en su condición de ser libre, de la protección a la individualidad, el ejercicio de las actividades que buscan su satisfacción, y que además, le exige un compromiso con la vida pública y una responsabilidad política frente a la realidad que lo interpela, se reconoce como parte funcional y activa del sistema de cooperación que se organiza y da forma a la política y a la realidad democrática en que vive. Esta clase superior de ciudadano se presenta como la figura que, producto de su naturaleza excepcional, se compromete con la vida pública, entra en contacto con los demás, hace uso de sus libertades políticas y vela por el fortalecimiento y protección de la esfera política; consecuente con su deber de ser partícipe de las decisiones políticas, se encuentra, no solamente en el derecho sino en la obligación de participar activamente en los ejercicios de la democracia, y se constituye como un superciudadano en la vida democrática, puesto que ésta es la única forma de permitir una verdadera consolidación de la democracia como sistema de gobierno. 


\section{El mediodía del superciudadano}

Zarathustra indica que la hora del "gran mediodía" es la señal que anuncia que el superhombre está próximo a arribar (Nietzsche, 2011: 510). Con esta figura el profeta enseña que el signo de la superación del hombre por fin está cerca, puesto que se han encontrado los compañeros de viaje idóneos ${ }^{9}$ para preparar el esperado comienzo de la era del superhombre. ¿En qué punto del día está entonces el súperciudadano? ¿Está cerca del medio día o todavía no ha amanecido en su mundo?

La filosofía política contemporánea ha denunciado la necesidad de replantear la figura del ciudadano en las democracias modernas. En efecto, el principio de la distinción propuesto por Madison señala que la ciudadanía debe desarrollar la democracia a través de la representación y defendió la capacidad de estos representantes para identificar de mejor manera el bien público; esta separación de la vida pública sostenida por el liberalismo tuvo que ver más con la necesidad de evitar que una multitud descontrolada de ciudadanos decidiendo sobre temas estatales, que con la imposibilidad práctica para que la ciudadanía obtuviera mecanismos de participación efectiva (Gargarella, 2002: 79). En contraste, el principio de la conexión (inicialmente argüido durante el siglo XVIII en Inglaterra) ha resurgido en medio del debate actual de la ciudadanía el cual pretende reconectar a los ciudadanos con sus instituciones democráticas y la vida pública (2002 86). La tradicional figura de la ciudadanía propuesta por el liberalismo, según la cual el status de ciudadano se otorga mediante la garantía de los derechos civiles y políticos que pretenden proteger a éste del poder imperante del Estado, ha sido rebatida por una renovada ciudadanía del corte republicano que aboga por la participación en las cuestiones políticas y democráticas; el status de ciudadano no se adquiere por consiguiente con la simple garantía de los derechos y la pertenencia a una comunidad normativa, sino que se adquiere en el efectivo ejercicio de estos derechos ${ }^{10}$.

De conformidad con lo expuesto, la reivindicación por la participación activa del ciudadano incluye tanto la tesis liberal de la igualdad ante la ley, y también el aspecto diferenciador del compromiso ético del ciudadano. Precisamente, David Miller sostiene frente a esta concepción cuatro premisas básicas: la igualdad de derechos es necesaria para que los ciudadanos puedan ocuparse tanto de sus cuestiones públicas como privadas; igualmente es necesario una serie de obligaciones legales que reglamenten algunas actuaciones humanas; la ciudadanía debe de jugar un rol activo en la promoción de intereses comunes y en la defensa de los derechos de otros miembros de la comunidad política; y finalmente, el ciudadano debe de aportar su contribución política tanto en los espacios democráticos formales como informales (Kartal, 2001: 125).

El cambio de paradigma resulta evidente, dado que el foco de atención ha cambiado al ciudadano. Anteriormente, se observaba con precaución la responsabilidad, protección y distancia que debía tener el Estado frente a sus ciudadanos; ahora, es el ciudadano quien debe de corresponder con los derechos que tiene para el sostenimiento del Estado democrático, el cual deja de ser esa figura amenazante de la individualidad humana, para pasar a ser el motor que facilita la realización de los ciudadanos por gracia de la consolidación de los valores democráticos. El abandono de la figura amenazante del Estado, no significa que se ha perdido completamente la posibilidad de abusos de poder o de violaciones a los derechos, sino un cambio en el paradigma de la concepción del Estado, el cual muta a una concepción más benevolente. Justamente, el triunfo de la sociedad burguesa sobre los gobiernos despóticos, generó una profunda desconfianza por las acciones del Estado,

\footnotetext{
${ }^{9}$ Zarathustra en este punto queda con tres compañeros de viaje: el águila, la serpiente y el león riente. Este último es el "signo" del superhombre. Probablemente el león riente hace referencia a dos afirmaciones que se hacen a lo largo del texto: primero, el superhombre sabe reírse de las tragedias del teatro y de la vida, lo que asevera la forma trágica de la vida humana y la actitud con la cual el superhombre puede asumir el sinsentido de la existencia; en segundo lugar, cuando Zarathustra alega que solamente se puede matar mediante la risa, estaría manifestando que este león riente significa que finalmente la naturaleza humana podrá morir para dar paso al superhombre.

${ }^{10}$ Sobre este debate véase la crítica que hace el modelo neo-republicano al sistema de la democracia representativa puede evidenciarse en (Hernández, 2002: 531).
} 
así pues, el ciudadano se planteó bajo la premisa de la independencia; ésta podría dedicarse por completo a su vida privada de negocios, profesiones liberales, o puede optar por hacer parte de la comunidad política de forma activa (Rubio, 2007:132).

Esta desconfianza hacia el Estado y los gobernantes se ve manifestada en el término accountability. Éste designa en el mundo anglosajón el concepto de la responsabilidad política. El Oxford Dictionay of English (2010) deriva la palabra del latín accomptare utilizado desde el siglo XIII para hacer referencia a la rendición de cuentas que debían hacer los administradores en función de cargos en el gobierno o en el manejo de dinero. Así entonces, históricamente los gobernantes han tenido que rendir cuentas sobre sus gestiones y por el uso de su poder político durante el tiempo que han fungido como representantes del pueblo. Ahora bien, el superciudadano debe de invertir igualmente esta fórmula, puesto que también debe plantearse la interrogante sobre qué ha hecho con sus derechos y libertades políticas para contribuir a la realización de los ideales democráticos. Se configura por consiguiente una equivalente responsabilidad política del ciudadano democrático. Se observa por lo tanto que el súperciudadano está en una posición privilegiada frente al tipo de ciudadano común; aquél tiene una participación activa en la política más allá de simplemente demandar derechos y libertades cuando éstas son vulneradas.

La actuación del superciudadano es la característica que lo diferencia de cualquier otra tipología de ciudadanía. El hecho de que la democracia haya encontrado en un principio asidero en la concepción de una ciudadanía liberal, no significa que éste sea el punto de llegada para la concreción de las virtudes democráticas. Correlativamente, Zarathustra pensó hallar en los "hombres superiores" la materialización de los ideales del superhombre (Nietzsche, 2011: 439484), no obstante, éstos terminan por ser inferiores al reto y por este motivo son echados del camino. "Los hombres superiores" son aquellos que tienen características superiores en su estructura moral frente a los demás hombres, puesto que son creadores de nuevos valores, arriesgados y anteponen su voluntad a la vida. Sin embargo, estos "hombres superiores" sucumben a su naturaleza humana inferior y vuelven a rezar, se han vuelto piadosos y han comenzado a adorar al asno (2011: 488).
Así mismo debe entonces el Estado democrático reconocer que solamente a través de una superciudadanía es posible mantener vigente la democracia. La enseñanza del superciudadano tiene la pretensión de ser una propuesta pedagógica, y una propuesta que plantee el interrogante sobre la sensibilización y el compromiso que se exige de cada ciudadano verdaderamente democrático; la educación no corresponde solamente a estudios científicos, fórmulas y acumulación de conocimiento sino que, en mayor medida, debe estar dirigida a crear hombres y ciudadanos responsables con la vida política, arrojados a seguir actuando por la realización de la democracia. El conocimiento científico es excluyente, sólo lo aprende quien quiera y pueda aprenderlo, pero el conocimiento cívico es un deber político.

La ciudadanía democrática es la aprehensión de rol político del ser humano. De este modo, se permite edificar una democracia desde la convivencia pacífica y la toma de decisiones en común, teniendo en cuenta los posibles y diversos puntos de vista; de la misma manera, ayuda a conformar un orden normativo y estatal que propugne por un reconocimiento amplio de las libertades; el respeto por las mayorías y las minorías democráticas se fundamenta en el papel como ciudadanos activos que buscan el bien general de la comunidad política; es gracias a la responsabilidad política del superciudadano que se puede eliminar la ciudadanía pasiva. Educar a los futuros ciudadanos no es más que el deber con el pasado, presente y futuro de la vida democrática.

Saber cuáles son las necesidades, los inconvenientes y de la sociedad en general, consiste en un ingrediente de vital importancia para el superciudadano; no se limita a atender únicamente a las libertades políticas individuales, sino que también es la consciencia permanente sobre la importancia de la actividad en la esfera pública, la búsqueda del bien común y el respeto por el otro. Por este motivo, el ciudadano debe tomar partida en la vida política y ponerse en movimiento y en contacto con las decisiones que competen a la ciudadanía:

La participación en el voto tiene un gran valor educativo; mediante la discusión política el obrero, cuyo trabajo es repetitivo en el estrecho horizonte de la fábrica, logra comprender la relación entre los acontecimientos lejanos y su interés personal, y establecer vínculos con ciudadanos diferentes de aquellos con los que trata 
cotidianamente y volverse un miembro consciente de una comunidad (Bobbio, 1986: 25).

La democracia propicia los espacios para que se pueda entablar una autentica discusión y diálogo entre los distintos ciudadanos; la democracia no puede prescindir de la participación activa de sus miembros. La superciudadanía es una condición para la viabilidad de los Estados democráticos; y es tal vez esta condicionalidad lo que sitúa a la democracia constantemente en situaciones complejas, puesto que en términos generales, la ciudadanía no responde de manera adecuada a las exigencias de ésta.

La excepcionalidad del superciudadano no radica solamente en lo extraordinario de sus capacidades, sino también en lo complejo de encontrar grupos de superciudadanos. Por esta razón, se delata que el superciudadano acaba por ser también un superhombre, porque aquél se introduce en la esfera pública a pesar de sus preocupaciones privadas. El hecho que el superciudadano deba saber mantener un equilibrio entre la esfera pública y privada, significa mucho más que una enseñanza, es sobre todo una vida heroica que se debate entre lo propio y lo político, entre lo apolíneo y lo dionisíaco.

La confrontación que vive el superciudadano entre el principio apolíneo y el principio dionisíaco es lo que determina el carácter estético de la ciudadanía democrática. Mientras que el principio apolíneo hace referencia al dios Apolo y significa la belleza, la verdad superior, el conocimiento verdadero, la mesura, la limitación a las emociones salvajes y el sosiego de la sabiduría (Nietzsche, 1973: 231); el principio dionisíaco recurre al dios Dionisio como representación de la embriaguez, el éxtasis, el olvido de sí mismo y la sobreabundancia de las emociones (1973: 232). La contradicción entre estas dos figuras lleva a que la existencia humana sea trágica, no obstante, es a través de la tragedia que se puede concebir la figura de un héroe que impone su voluntad y asume como propia esa incoherencia; el contenido de la tragedia "es, en primer término, un acontecimiento épico, con la glorificación del héroe luchador" (1973: 186). Ahora bien, el que Nietzsche afirme que "la meta del Estado es Apolo y la meta de la existencia es Dionisio" (2004: 65), lleva a pensar que la superciudadanía se divide necesariamente entre corresponder a las obligaciones, a la rectitud que supone lo apolíneo de su vida, y a la vez tiene un constante retorno a su esencia animal y dionisíaca. El principio apolíneo niega el placer primordial de la existencia, y es por virtud de esta negación que también le otorga su elemento heroico:

[...] el único Dionisio verdaderamente real aparece con una pluralidad de figuras, con la máscara del héroe que lucha, y, por así decirlo, aparece preso en la red de la voluntad individual. En su forma de hablar y de actuar ahora, el dios que aparece se asemeja a un individuo que yerra, anhela y sufre: y el que llegue a aparecer con tal precisión y claridad épicas es efecto del Apolo intérprete de sueños, que mediante aquella apariencia simbólica le da al como una interpretación de su estado dionisíaco. (1973: 97)

Es condición heroica de la ciudadanía fue observada por Arendt. Justamente, la participación política implica especialmente el abandono del hogar y de la familia para hacer parte de la comunidad política, este atrevimiento conlleva el riesgo de dejar lo seguro, el lugar en donde se garantizan las apremiantes necesidades vitales, para someterse al azar de la aventura. En términos políticos el hombre renuncia a los placeres de su existencia para corresponder a una vida política que le obliga a suprimir sus emociones desbordantes, sus preocupaciones individuales:

\footnotetext{
“[e]sta convicción de que sólo puede ser libre quien esté dispuesto a arriesgar su vida jamás ha desaparecido del todo de nuestra conciencia; y lo mismo hay que decir del vínculo de lo político con el peligro y el atrevimiento en general. La valentía es la primera de todas las virtudes políticas y todavía hoy forma parte de las pocas virtudes cardinales de la política, ya que únicamente podemos acceder al mundo público común a todos nosotros, que es el espacio propiamente político, si nos alejamos de nuestra existencia privada y de la pertenencia a la familia a la que nuestra vida está unida" (Arendt, 1997: 73-74).
}

Educar para una superciudadanía deriva también en educar el valor y la estética del héroe que sacrifica aquello que le pertenece para conseguir, en palabras de Nietzsche, una meta superior. Aunque está lleno de obstáculos el camino, Nietzsche nunca renuncia completamente a continuarlo, él está a la espera del signo que indique la hora del mediodía que anuncia la venida del superhombre; en esta misma actitud debe de estar la democracia ¿Por qué desistir de una democracia vivida con superciudadanos? “ ¿No es necesario tener ideales? Ciertamente son necesarios los ideales... tan necesario hoy que nos volvemos cada vez más conscientes de este destino común y deberíamos, 
por la poca luz de la razón que ilumina nuestro camino, actuar en consecuencia" (Bobbio, 1986: 30). La búsqueda de los ideales y valores democráticos modernos indican el camino que se debe de seguir, es la permanente apelación a los superciudadanos; es la figura heroica y valiente de estos superhombres el ideal de cada ciudadano que se compromete día a día en su rol de ser político.

\section{Referencias}

Arendt, H. (1997). ¿Qué es política? Barcelona: Piados.

Arendt, H. (2005). La condición humana. Barcelona: Ediciones Piados Ibérica.

Arteta, A. (2009). Tópicos Fatales (o las peligrosas perezas de la ciudadanía). En Democracia, ciudadanía y educación. Sevilla: Ediciones Akal.

Bauman, Z. (2003). Modernidad líquida. México D.F: Fondo de cultura económica de México.

Bobbio, N. (1986). El futuro de la democracia. México: Fondo de cultura económica de México.

Bovero, M. (2002). Ciudadanía y derechos humanos. Puebla: Editorial Cajica.

Oxford Dictionary OfEnglish. (2010). Oxford University Press.

Gargarella, R. (2002). La comunidad igualitaria y sus enemigos. En Republicanismo contemporáneo: igualdad, democracia deliberativa y ciudadanía. Bogotá: Siglo de Hombre Editores.

Habermas, J. (1999). Tres Modelos Normativos de Democracia. En La inclusión del otro. Barcelona: Paidós.

Hernández, A. (2002). El pensamiento republicano frente a los déficit de la democracia liberal. En Republicanismo contemporáneo: igualdad, democracia deliberativa y ciudadanía. Bogotá: Siglo del Hombre Editores.

Kartal, F. (2001-2002). Liberal and republican conceptualizations of citizenship: a theoretical inquiry. Turkish Public Administration Annual Vol. 27-28.

Medellín, C. (2009). Lecciones de derecho romano. Bogotá: Legis.
Molina, C. (2009). Derecho constitucional general. Medellín: Universidad de Medellín.

Mougán, J. C. (2009). Hacia una teoría de la educación para una ciudadanía democrática. En Democracia, ciudadanía y educación. Sevilla: Ediciones Akal.

Nietzsche, F. (2011). Así hablo Zarathustra. Madrid: Alianza Editorial.

Nietzsche, F. (1993). Ecce homo. Madrid: Alianza Editorial.

Nietzsche, F. (1973). El nacimiento de la tragedia. Madrid: Alianza Editorial.

Nietzsche, F. (2004). Fragmentos Póstumos sobre Política. Madrd: Editorial Trotta.

Ortega y Gasset, J. (1958). Ensimismamiento y alteración. En Obras completas 1902-1958 vol. 5. Madrid: Altamira.

Peña, J. (2009). El retorno de la virtud cívica. En Democracia, Ciudadanía y Educación. Sevilla: Ediciones Akal.

Rubio Carracedo, J. (2007). Teoría Crítica de la Ciudadanía Democrática. Madrid: Editorial Trotta.

Sassen, S. (2002). The Repositioning of Citizenship: Emergent Subjects and Spaces for Politics. Berkeley Journal of Sociology, Vol. 46 .

Savater, F. (2000). Conferencia: Ética y ciudadanía. Revista de humanidades: Tecnológico de Monterrey, número 8 (8).

Savater, F. (2007). Diccionario del ciudadano sin miedo a saber. Barcelona: Ariel.

Revista. Humanismo.Soc. 2014; Volumen 2 (2): 38-51. 